\title{
Preparation of nanogel-immobilized porous gel beads for affinity separation of proteins: fusion of nano and micro gel materials
}

\author{
Yu Hoshino', Yuka Arata ${ }^{1}$, Yusuke Yonamine ${ }^{2}$, Shih-Hui Lee ${ }^{2}$, Aki Yamasaki ${ }^{3}$, Ryousuke Tsuhara ${ }^{3}$, \\ Katsuhiko Yano $^{3}$, Kenneth J Shea ${ }^{2}$ and Yoshiko Miura ${ }^{1}$
}

We describe the preparation and evaluation of nanogel-immobilized porous gel beads (GB) for application as a protein purification medium. Nanogel particles (NP) that bind with the Fc fragment of immunoglobulin G (IgG) were immobilized on the pore surface of macroporous hard GB containing quaternary ammonium cations on the surface via multipoint electrostatic interactions. The amount of NPs that were irreversibly immobilized in $1 \mathrm{ml}$ of GB slurry was determined to be $\sim 30 \mathrm{mg}$ using fluorescent-labeled NPs. Images obtained via scanning electron microscopy established that the NPs were uniformly immobilized on the surface of the pores without blocking the macropores. The model target protein (IgG) was reversibly captured by the NPimmobilized GBs through NP-lgG interactions. NP-immobilized GBs have potential applications as novel affinity purification media for proteins, combining inexpensive and stable ligands with high-performance supports.

Polymer Journal (2015) 47, 220-225; doi:10.1038/pj.2014.101; published online 26 November 2014

\section{INTRODUCTION}

Porous microbeads immobilized with affinity ligands that selectively bind to target proteins are important as the purification media for proteins. For example, antigens and antibodies can be purified via affinity chromatography using antibody or antigen-immobilized beads as an affinity separation medium. The affinity purification process of monoclonal antibodies using protein A-immobilized beads is one of the most important processes in the production of monoclonal antibody drugs.

Synthetic ligands that strongly bind to specific proteins are of great interest as stable and inexpensive alternatives to biomacromolecular ligands. ${ }^{1,2}$ Schrader and colleagues have reported that synthetic polymer hosts that bind to specific domains of target proteins ${ }^{3,4}$ can be prepared by copolymerizing an optimized combination of monomers that interact strongly with side chains of specific amino acids. Haag and colleagues reported that dendritic polymer ligands for specific proteins could be prepared by tuning the type and combination of functional groups available on the surface of the polymers. ${ }^{5-8}$ Shea and colleagues reported that multifunctional nanogel particles (NPs) polymerized with a combination of functional monomers capture target peptides, ${ }^{9-12}$ proteins ${ }^{13-15}$ and specific domains of proteins ${ }^{16}$ via a combination of multipoint electrostatic, hydrophobic, aromatic $^{17}$ and/or hydrogen binding ${ }^{18}$ interactions. Target affinity can be enhanced by optimizing the feed ratio of functional monomers, ${ }^{19}$ by molecular imprinting polymerization ${ }^{20,21}$ and/or by affinity purification procedures. ${ }^{22}$ It has also been reported that porous membranes polymerized with functional monomers containing carbohydrates can be used as affinity separation media for lectins. ${ }^{23-25}$

Solid supports for affinity purification media must be carefully designed to achieve an efficient purification process. ${ }^{26}$ Porous materials with large surface areas and pore diameters larger than that of the target protein (>30 nm for IgG), enable high binding capacity and fast adsorption kinetics. ${ }^{27}$ The supports must be hydrophilic (ideally a hydrophilic gel such as agarose) to reduce non-specific adsorption of proteins on the surface. ${ }^{28}$ However, soft and hydrophilic gel beads (GB) are not suitable for high flow rates and/or large-scale processes because the gel structures would easily collapse under the backpressure and would become stuck in the column. ${ }^{29}$

Macroporous and hydrophilic GB stabilized by cross-linkers are ideal solid supports for high-capacity, large-scale and fast protein purification processes. ${ }^{30}$ We have reported that hydrophilic macroporous GB with a high-pressure resistance can be prepared by the suspension polymerization of methacrylate and a cross-linker in the presence of porogens. ${ }^{31}$ The GB have a large pore diameter of $\sim 50 \mathrm{~nm}$ and a large surface area of $50 \mathrm{~m}^{2} \mathrm{~g}^{-1}$, which enable $1 \mathrm{ml}$ of gel slurry to adsorb $50 \mathrm{mg}$ of IgG. $^{32}$ Furthermore, the spherical and rigid beads enable an extremely high flow rate purification process, with a flow rate of $10 \mathrm{~m} \mathrm{~min}^{-1}$

In this study, we report a novel affinity separation medium for proteins that consist of macroporous GB as the solid support and multifunctional NPs as the affinity ligands. Poly- $N$-isopropylacrylamide NPs copolymerized with an optimized feed ratio of $\mathrm{N}$-tert-

${ }^{1}$ Department of Chemical Engineering, Kyushu University, Fukuoka, Japan; ${ }^{2}$ Department of Chemistry, University of California, Irvine, CA, USA and ${ }^{3}$ Mitsubishi Chemical Corporation, Tokyo, Japan

Correspondence: Professor Y Hoshino, Department of Chemical Engineering, Kyushu University, 744 Motooka, Nishi-ku, Fukuoka 819-0395, Japan.

E-mail: yhoshino@chem-eng.kyushu-u.ac.jp

Received 7 August 2014; revised 2 September 2014; accepted 17 September 2014; published online 26 November 2014 
butylacrylamide (TBAm) and acrylic acid (AAc) were synthesized as affinity ligands for the Fc fragment of IgG. ${ }^{17}$ Macroporous GBs with a pore diameter of $50 \mathrm{~nm}$ and a quarterly ammonium group immobilized on the pore surface were used as solid supports. A single layer of NPs was immobilized on the pore surface using multipoint electrostatic interactions between the quarterly ammonium cations and the carboxylate anions. ${ }^{33-35}$ The amount of NPs immobilized on the GBs was calculated from the concentration of NPs (measured using fluorescently labeled NPs) remaining in the solution after the immobilization process. The morphology of NP-immobilized pore structures was observed using a scanning electron microscope. Finally, the amount of IgG, which can be reversibly captured by the NPimmobilized GBs, was quantified.

\section{EXPERIMENTAL PROCEDURE}

\section{Materials}

Most of the chemicals were obtained from commercial sources. $N, N, N^{\prime}$, $N^{\prime}$-tetramethylethylenediamine, dansyl chloride, triethylamine and ammonium persulfate were purchased from Sigma-Aldrich Japan (Tokyo, Japan) $\mathrm{N}$ isopropylacrylamide (NIPAm), AAc, TBAm and sodium dodecyl sulfate were obtained from Wako Pure Chemical Industries (Osaka, Japan), Ltd. N,N '-methylenebisacrylamide (BIS), ethylenediamine and methacryloyl chloride were purchased from Tokyo Chemical Industry Co. Ltd., (Tokyo, Japan), Thermo Fisher Scientific K. K. (Waltham, MA, USA) and Alfa Aesar (Ward Hill, MA, USA), respectively. NIPAm was recrystallized from hexanes. The porous polymer beads (MCI gel CQA35P) were provided by Mitsubishi Chemical Corporation (Tokyo, Japan) and were washed with an excess amount of water, phosphate buffered saline (PBS; $10 \mathrm{~mm}$ phosphate, $137 \mathrm{~mm} \mathrm{NaCl}$ and $27 \mathrm{~mm} \mathrm{KCl}, \mathrm{pH}$ 7.4), an aqueous solution of $\mathrm{NaOH}(0.1 \mathrm{M})$ and water, two to three times each before use. The water used in this study was purified using a Millipore water purification system (Merck, Darmstadt, Germany). Other chemicals were used as received.

\section{Synthesis of $\mathrm{N}$-(2-Aminoethyl)-5-(dimethylamino)-1-naphthalene sulfonamide}

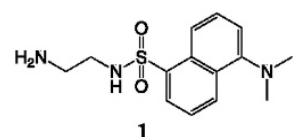

The procedure reported by Shea and colleagues ${ }^{19}$ was modified to prepare compound 1. A solution of dansyl chloride $(0.94 \mathrm{~g}, 3.47 \mathrm{mmol})$ in dry tetrahydrofuran (THF) $(75 \mathrm{ml})$ was added dropwise to a cooled $\left(0^{\circ} \mathrm{C}\right)$ solution of ethylenediamine $(2.32 \mathrm{ml}, 34.7 \mathrm{mmol})$ in dry THF $(150 \mathrm{ml})$. The reaction mixture was stirred at $0{ }^{\circ} \mathrm{C}$ for $3 \mathrm{~h}$, followed by the addition of aqueous $\mathrm{KOH}$ $(10 \mathrm{ml}, 1 \mathrm{~N})$. The THF was evaporated and the aqueous layer was extracted with $\mathrm{CH}_{2} \mathrm{Cl}_{2}(5 \times 50 \mathrm{ml})$. The combined organic layers were dried over $\mathrm{MgSO}_{4}$ and evaporated to leave a pale yellow-green solid. Recrystallization from benzene provided light-green needles $(0.333 \mathrm{~g}, 1.14 \mathrm{mmol}, 32 \%$; proton nuclear magnetic resonance $\left(\mathrm{CDCl}_{3}\right) \delta 8.54(\mathrm{~d}, J=8.5 \mathrm{~Hz}, 1 \mathrm{H}), 8.30(\mathrm{~d}, J=8.6 \mathrm{~Hz}, 1 \mathrm{H})$, $8.24(\mathrm{~d}, J=7.3 \mathrm{~Hz}, 1 \mathrm{H}), 7.55(\mathrm{~m}, 2 \mathrm{H}), 7.17(\mathrm{~d}, J=7.3 \mathrm{~Hz}, 1 \mathrm{H}), 2.88(\mathrm{~m}, 8 \mathrm{H})$ and $2.69(\mathrm{~m}, 2 \mathrm{H}))$.

Synthesis of N-[2-[[[5-(Dimethylamino)-1-naphthalenyl]sulfonyl] amino]ethyl]-2-propenamide (DNS methacrylate)

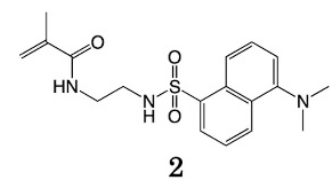

Methacryloyl chloride $(0.112 \mathrm{ml}, 1.36 \mathrm{mmol})$ and triethylamine $(0.160 \mathrm{ml}$, $1.36 \mathrm{mmol}$ ) were added to a solution of $\mathrm{N}$-(2-Aminoethyl)-5-(dimethylamino)1-naphthalene sulfonamide $(0.333 \mathrm{~g}, 1.14 \mathrm{mmol})$ in THF $(33 \mathrm{ml})$ at room temperature. The reaction mixture was stirred at room temperature for $16 \mathrm{~h}$, followed by the addition of more methacryloyl chloride $(0.056 \mathrm{ml}, 0.68 \mathrm{mmol})$ and triethylamine $(0.08 \mathrm{ml}, 0.68 \mathrm{mmol})$. The reaction mixture was further stirred at room temperature for $3 \mathrm{~h}$, and the salts were then filtered and washed with THF. The combined filtrate was evaporated and purified via flash chromatography (1:1 ethyl acetate: ethyl ether), which yielded DNS methacrylate as a light-green solid $(0.170 \mathrm{~g}, 0.470 \mathrm{mmol}, 41 \%$; proton nuclear magnetic resonance $\left(\mathrm{CDCl}_{3}\right) \delta 8.52(\mathrm{~d}, J=8.5 \mathrm{~Hz}, 1 \mathrm{H}), 8.27(\mathrm{~d}, J=8.6 \mathrm{~Hz}, 1 \mathrm{H}), 8.19(\mathrm{dd}$, $J=1.0$ and $7.3 \mathrm{~Hz}, 1 \mathrm{H}), 7.50(\mathrm{~m}, 2 \mathrm{H}), 7.16(\mathrm{~d}, J=7.5 \mathrm{~Hz}, 1 \mathrm{H}), 6.58(\mathrm{br} \mathrm{t}$, $J=5.2 \mathrm{~Hz}, 1 \mathrm{H}), 6.15(\mathrm{t}, J=5.9 \mathrm{~Hz}, 1 \mathrm{H}), 5.59(\mathrm{~s}, 1 \mathrm{H}), 5.22(\mathrm{~s}, 1 \mathrm{H}), 3.36(\mathrm{~m}$, $2 \mathrm{H}), 3.07(\mathrm{~m}, 2 \mathrm{H}), 2.87(\mathrm{~s}, 6 \mathrm{H})$ and $1.81(\mathrm{~s}, 3 \mathrm{H}))$.

\section{Preparation of NPs}

To improve the stability of NPs in water, NPs with different degrees of crosslinking ( $\mathrm{X}$ mol\%, where $\mathrm{X}=2,5,10$ and 20$)$ were prepared. NIPAm $(40-\mathrm{X}$ $\mathrm{mol} \%)$, AAc $(35.6 \mu \mathrm{l}, 20 \mathrm{~mol} \%)$, TBAm (133 mg, $40 \mathrm{~mol} \%)$, Bis (X mol\%), DNS methacrylate $(94 \mu \mathrm{g}, 0.01 \mathrm{~mol} \%)$ and sodium dodecyl sulfate $(80 \mathrm{mg})$ were dissolved in water $(400 \mathrm{ml})$. TBAm and DNS methacrylate were dissolved in ethanol $(4 \mathrm{ml})$ and acetone $(5 \mathrm{ml})$, respectively, prior to being added to the monomer solution, resulting in a final monomer concentration of $6.5 \mathrm{~mm}$. The resulting solution was degassed by bubbling nitrogen through the reaction mixture for $120 \mathrm{~min}$. Following the addition of ammonium persulfate (APS, $240 \mathrm{mg}$ in $4 \mathrm{ml}$ water) and $N, N, N^{\prime}, N^{\prime}$-tetramethylethylenediamine $(120 \mu \mathrm{l})$ to the solution prepared above, the polymerization was carried out at $23-25^{\circ} \mathrm{C}$ for $17 \mathrm{~h}$ under a nitrogen atmosphere. The polymerized solutions were purified by dialysis (molecular weight cut off-12000-14000) against an excess of water (changed over three times a day) for $>4$ days. The yield of the NPs was determined by measuring the weight of the NPs obtained by lyophilization of $40 \mathrm{ml}$ of the dialyzed solution. The dilution in dialysis was corrected. The hydrodynamic diameter of the NPs in aqueous solutions at $25^{\circ} \mathrm{C}$ was determined via dynamic light scattering (Zetasizer Nano ZS, Malvern Instruments Ltd., Worcestershire, UK). The solution temperature was preequilibrated for $2 \mathrm{~min}$ at $25^{\circ} \mathrm{C}$. Subsequently, the measurements were taken in triplicate at each solution temperature at $2 \mathrm{~min}$ intervals. All dynamic light scattering data met the quality criteria set by Malvern. The NP solutions were stored in a refrigerator at $5^{\circ} \mathrm{C}$.

\section{Adsorption of NPs on beads}

A slurry of porous polymer beads (1001) was added to a solution of NPs $(3.4 \mathrm{mg})$ in water $(7.1 \mathrm{ml})$ at room temperature. The mixture was stirred at 70 r.p.m. at room temperature using a shaker. The concentration of NPs remaining in the supernatant was determined by the fluorescence intensity of the dansyl group measured using a fluorescent microplate reader (Thermo Fisher Scientific K.K., Varioskan Flash) or a fluorescent spectrometer (JASCO, Tokyo, Japan). The unbound NPs were removed from the solution by replacing the solution with water four times.

\section{Washing of NP-adsorbed beads}

A slurry of the NP-adsorbed porous polymer beads $(\sim 100 \mu \mathrm{l})$ was incubated with PBS $(1 \mathrm{ml})$ once for $5 \mathrm{~min}$, seven times for $1 \mathrm{~h}$, and three times for $3 \mathrm{~h}$. The slurry was further washed with an acidic buffer (100 mM glycine- $\mathrm{HCl}, 1 \mathrm{ml})$ three times for $1 \mathrm{~h}$.

\section{Adsorption of IgG on NP-immobilized porous beads}

NP-immobilized porous beads were equilibrated with PBS and then washed with an excess amount of water. A slurry of the NP-immobilized porous polymer beads $(100 \mu \mathrm{l})$ was incubated with an aqueous solution of IgG (0.5 $\left.\mathrm{mg} \mathrm{ml}^{-1}, 1 \mathrm{ml}\right)$ at room temperature. The mixture was incubated at room temperature using a shaker for $3 \mathrm{~h}$. The concentration of IgG remaining in the supernatant was quantified by measuring the ultraviolet (UV) absorbance at $280 \mathrm{~nm}$ using a UV-visible (UV-Vis) spectrometer (JASCO). The adsorption of IgG on the porous beads without NPs was also tested as a control experiment.

\section{Desorption of IgG from NP-immobilized porous beads}

After incubation with IgG, the slurry of NP-immobilized porous polymer beads $(\sim 100 \mu \mathrm{l})$ was washed four times with water to remove weakly bound IgG from 
the beads. The beads were then incubated with an acidic buffer $(100 \mathrm{~mm}$ glycine- $\mathrm{HCl}, 1 \mathrm{ml}$ ) at room temperature. The mixture was incubated at room temperature using a shaker for $3 \mathrm{~h}$. The concentration of IgG released into the supernatant was quantified by measuring the UV absorbance at $280 \mathrm{~nm}$ using a $\mathrm{UV}-\mathrm{Vis}$ spectrometer (JASCO). The desorption of IgG from the porous beads without NPs was also tested as a control experiment.

\section{SEM imaging}

GBs were deposited by sputtering with $\mathrm{Pt} / \mathrm{Pd}$ (6/4) targets using Ion Sputter E-1030 (Hitachi High-Technologies Co., Tokyo, Japan). After the deposition of the GBs, they were imaged using a scanning electron microscope (SEM ULTRA55, Carl Zeiss, Oberkochen, Germany, $2 \mathrm{kV}$ ).

\section{RESULTS AND DISCUSSION}

\section{Preparation of NPs}

NPs that interact with the Fc fragment of IgG with a dissociation constant of $\sim 10 \mathrm{~nm}$ were used as affinity ligands in this study. ${ }^{17}$ It has been reported that certain NPs are capable of interacting with the Fc fragment via a combination of hydrophobic and electrostatic interactions. ${ }^{17}$ The NPs were prepared in an aqueous solution by pseudo-precipitation polymerization of NIPAm (38 mol\%), TBAm (40 mol\%), AAc (20 mol\%) and BIS ( $2 \mathrm{~mol} \%$ ) using sodium dodecyl sulfate as the stabilizer. To quantify the amount of NPs immobilized on GBs, we labeled NPs with dansyl groups by copolymerizing dansylated methacrylamide. Dansyl methacrylamide was synthesized using the method reported. ${ }^{22}$ When the NPs were polymerized with greater than $0.1 \mathrm{~mol} \%$ of dansyl methacrylamide, a mono-modal size distribution of NPs was not obtained because of the tendency of the NPs to aggregate during the preparation process. When the NPs were polymerized with $0.01 \mathrm{~mol} \%$ of dansyl methacrylamide, NPs with a mono-modal size distribution were obtained. However, some aggregates were observed when the NPs were incubated at $25^{\circ} \mathrm{C}$ for approximately $10 \mathrm{~h}$ (Figure 1 ). To improve the stability, NPs with a larger feed ratio of cross-linker (5, 10 and $20 \mathrm{~mol} \%$ BIS) were prepared. The NPs polymerized with greater than $5 \mathrm{~mol} \%$ of BIS showed a mono-modal size distribution at $25^{\circ} \mathrm{C}$ for more than $20 \mathrm{~h}$ (Table 1, Figure 1). The detection limits of $0.01 \mathrm{~mol} \%$ dansylated NPs in aqueous solution were 10 and $0.5 \mu \mathrm{g} \mathrm{ml}^{-1}$ when measured using a fluorescent plate reader and a fluorescent spectrometer, respectively.

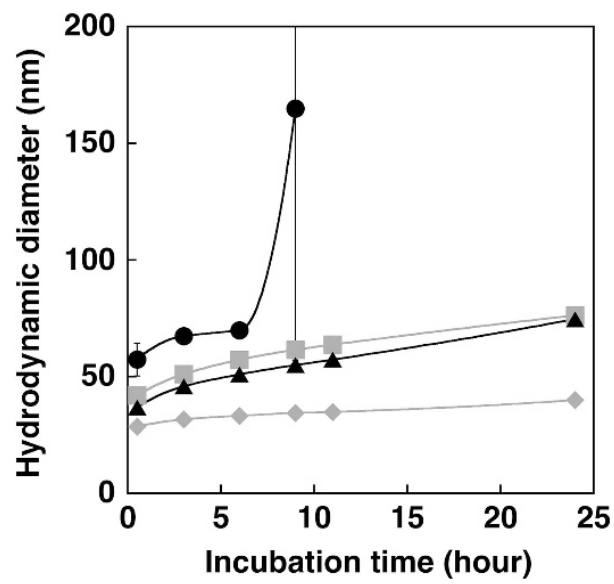

Figure 1 Time profile of the hydrodynamic diameter of 2, 5, 10 and $20 \mathrm{~mol}$ $\%$ cross-linked nanogel particles, represented by black circles, gray squares, black triangles and gray diamonds, respectively, in water at $25^{\circ} \mathrm{C}$.

\section{Adsorption of NPs on GBs}

Lyon and colleagues have reported that a monolayer of NPs consisting of NIPAm and AAc can be formed by the electrostatic deposition of negatively charged NPs on a positively charged glass surface modified with quaternary ammonium cations (99-101). Utilizing this idea in Lyon's report, we attempted to immobilize NPs on the pore surface of GBs via electrostatic deposition. Macroporous poly methacrylate-based GBs $(30 \mu \mathrm{m})$ with a pore diameter of $50 \mathrm{~nm}$ and containing a quaternary ammonium group immobilized on the pore surface were used as the solid support.

Figure 2 shows the time profile of the concentration of NPs measured with the fluorescence intensity of the supernatant when an aqueous solution of NPs $(3.4 \mathrm{mg}, 7.1 \mathrm{ml})$ was incubated with $100 \mu \mathrm{l}$ of the GB slurry at room temperature. The concentration of all NPs, regardless of the degree of cross-linking, decreased dramatically after incubating for several hours, indicating the adsorption of NPs on the GBs. The adsorption kinetics of slightly aggregated and relatively larger NPs polymerized with $2 \mathrm{~mol} \%$ BIS was slower than that of stable and smaller NPs (polymerized with 5, 10, $20 \mathrm{~mol} \% \mathrm{BIS}$ ). This result indicates that the NPs must be small enough to diffuse immediately into the macropores of the GBs.

Scanning electron microscope images of the GBs before and after adsorption of nanogel particles are shown in Figure 3. Figures $3 \mathrm{~b}$ and $\mathrm{d}$ show little aggregation of NPs on or around the GBs. From this result, combined with the quantitative adsorption

Table 1 Composition, yield and hydrodynamic diameter of NPs

\begin{tabular}{lccccccc}
\hline & \multicolumn{7}{c}{ Feed ratio of functional monomers (mol\%) } \\
\cline { 2 - 6 } NP\# & NIPAm & TBAm & AAC & Dansyl & Bis & Yield (\%) & Diameter (nm) \\
\hline NP1 & 37 & 40 & 20 & 0.01 & 2 & 41 & $57.3 \pm 7.0$ \\
NP2 & 35 & 40 & 20 & 0.01 & 5 & 100 & $42.0 \pm 0.1$ \\
NP3 & 30 & 40 & 20 & 0.01 & 10 & 100 & $36.9 \pm 0.3$ \\
NP4 & 20 & 40 & 20 & 0.01 & 20 & 100 & $28.6 \pm 0.4$ \\
\hline
\end{tabular}

Abbreviations: AAc, acrlamide; NIPAm, N-isopropylacrylamide; NPs, nanogel particle; TBAm, $N$-tert-butylacrylamide.

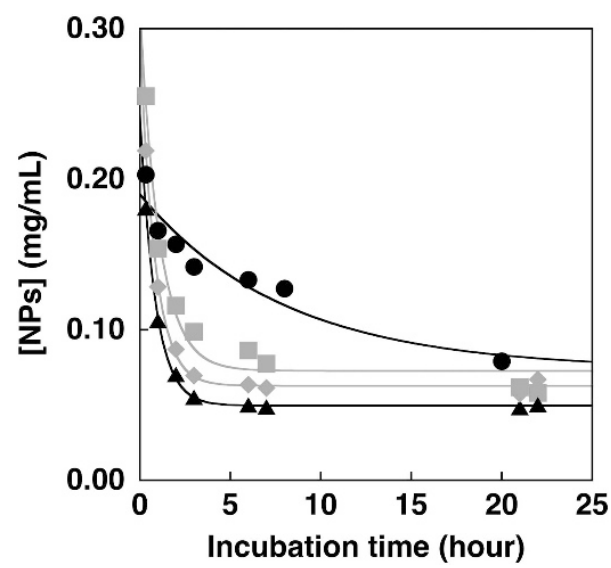

Figure 2 Time profile of 2, 5, 10 and 20 mol\% cross-linked non (represented by black circles, gray squares, black triangles and gray diamonds, respectively) quantified by measuring the fluorescence intensity in the supernatant when an aqueous solution of the nanogel particles $(3.4 \mathrm{mg}$, $7.1 \mathrm{ml}$ ) was incubated with $100 \mu \mathrm{l}$ of the gel beads slurry at room temperature. 
a

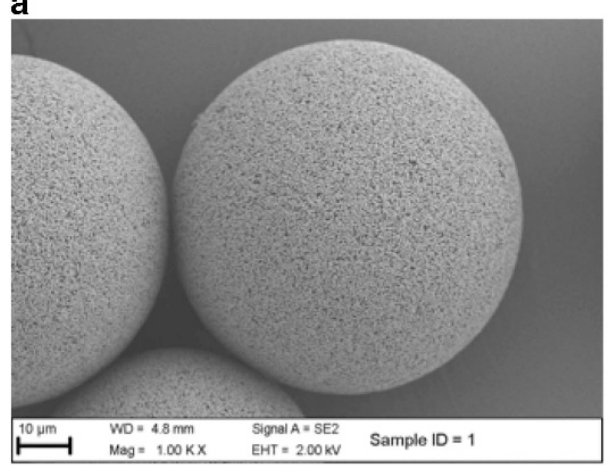

c

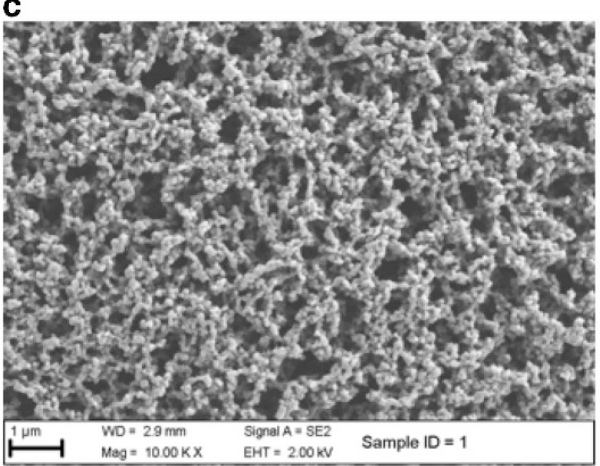

e

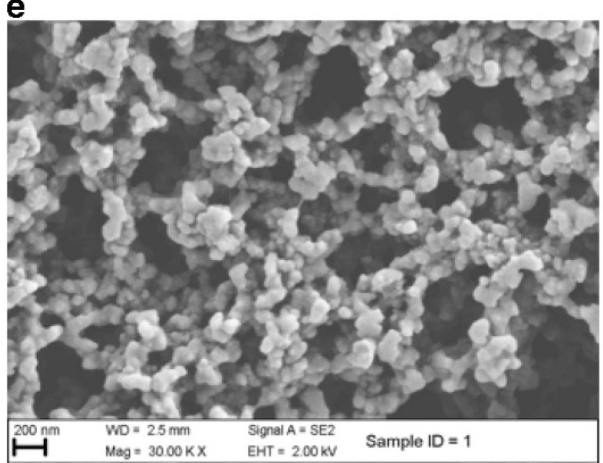

b

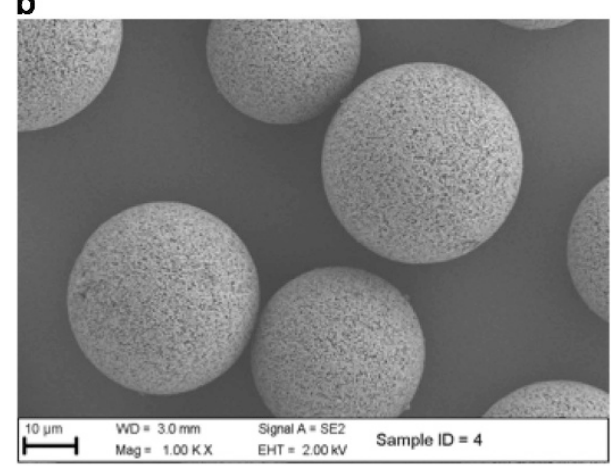

d
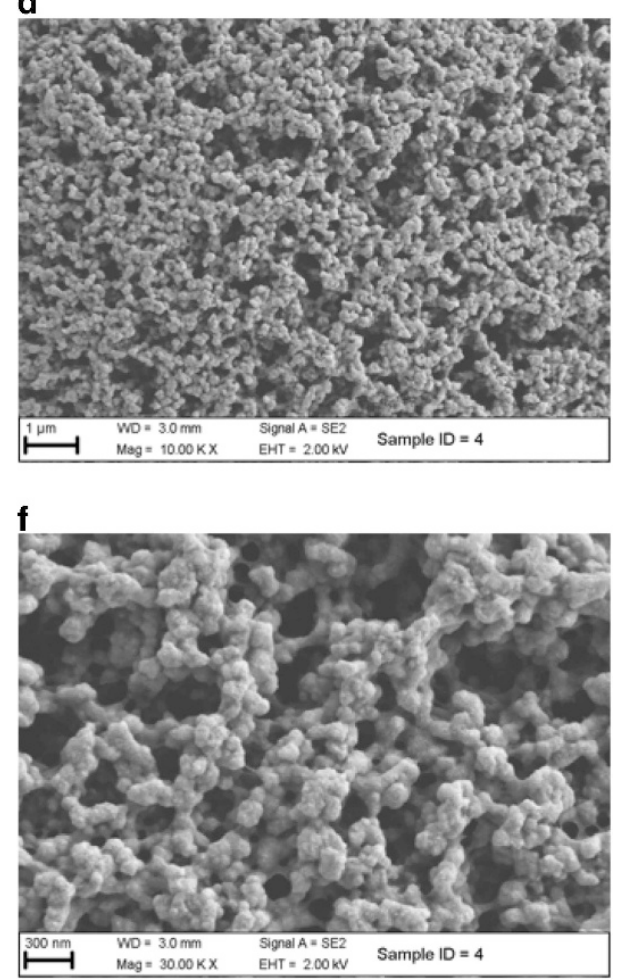

Figure 3 Scanning electron microscope images of gel beads before ( $\mathbf{a}, \mathbf{c}$ and $\mathbf{e}$ ) and after ( $\mathbf{b}, \mathbf{d}$ and $\mathbf{f}$ ) adsorption of NP1.

results from fluorescent measurement, it was confirmed that NPs were adsorbed on the GBs without forming aggregation products. Figure $3 \mathrm{e}$ and $\mathrm{f}$ indicate that the surface morphology of the pore structures after adsorption of the NPs were less angulated than the surface morphology before adsorption, although none of the pores were filled by the NPs. The apparent surface roughness of the NPs-immobilized pore surface seemed to be comparable to that of the mono-layered dried NPs films $(<10 \mathrm{~nm}),{ }^{10,19,20}$ suggesting that the surface of GBs were coated with NPs. From those results, it was established that NP-adsorbed macroporous GBs could be prepared simply by incubating negatively charged NPs and positively charged GBs in water.

\section{Desorption of NPs}

In the industrial IgG purification process, IgG is captured by protein A-immobilized beads at a neutral $\mathrm{pH}$ value of $\sim 7$ and eluted with an acidic buffer with a $\mathrm{pH}$ in the range of $2-3$. During the capture and elution process, it is important to ensure that bleeding of the affinity ligand is minimized. To prevent bleeding of the NPs during the IgG capture and elution process, the NP-adsorbed beads were carefully pre-washed with buffers with $\mathrm{pH}$ of 7.4 and 2.3 , respectively, to remove weakly adsorbed NPs.

The amount of NPs remaining on the surface of the GBs after the prewashing process is plotted in Figure 4 . When the GBs were initially washed with PBS for $1 \mathrm{~h}$, a significant amount of NPs were desorbed from the GBs. However, little desorption was observed after washing five times for $3 \mathrm{~h}$, even when the GBs were washed with PBS and an acidic buffer ( $\mathrm{pH}$ 2.3). This result indicates that most of the weakly adsorbed NPs can be removed by washing with PBS approximately five times. The amount of NPs that were irreversibly immobilized on the porous GBs was determined to be $\sim 30 \mathrm{mg} \mathrm{ml}^{-1}$. Although this amount is comparable to the amount of IgG that can be captured by the protein A-immobilized porous GBs, it is three times smaller than the amount of protein that can be captured by the porous ionexchange GBs. ${ }^{31,32}$ 


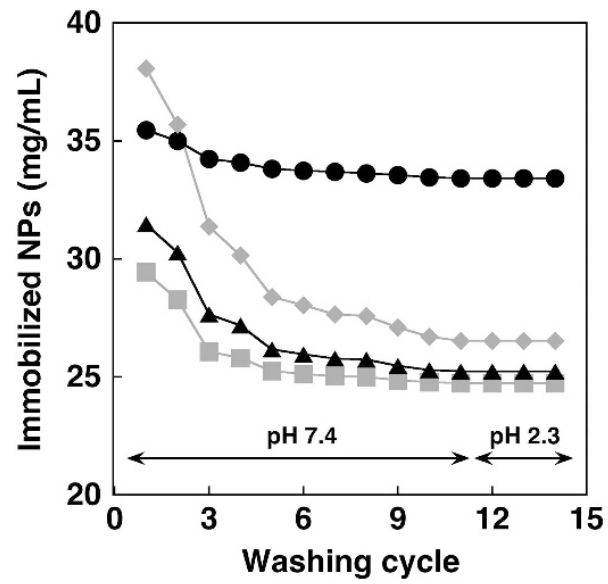

Figure 4 Cross-linked nanogel particles in 2, 5, 10 and $20 \mathrm{~mol} \%$ (represented by black circles, gray squares, black triangles and gray diamonds, respectively) remaining on the surface of gel beads after the prewashing process.
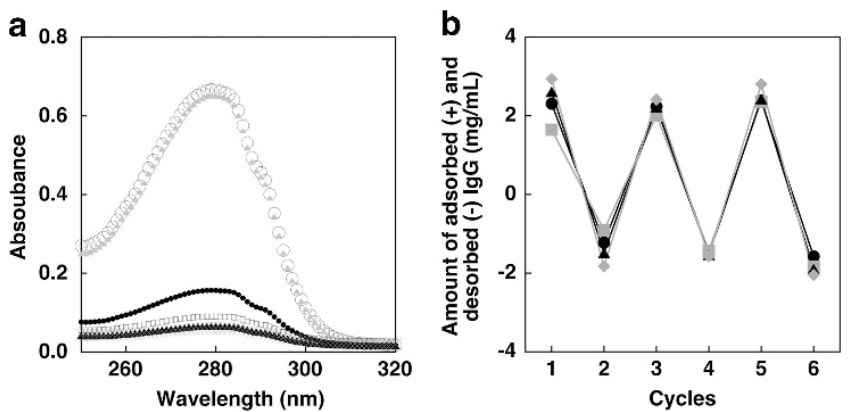

Figure 5 (a) Ultraviolet-visible absorption spectra of an aqueous solution of immunoglobulin before (circle) and after incubation with 2, 5, 10 and 20 mol\% cross-linked nanogelparticle-immobilized gel beads (represented by black circles, gray squares, black triangles and gray crosses, respectively) and gel beads without nanoparticles (represented by gray triangles). (b) Amount of immunoglobulin reversibly adsorbed and desorbed by 2, 5, 10 and $20 \mathrm{~mol} \%$ cross-linked nanogelparticle-immobilized gel beads (represented by black circles, gray squares, black triangles and gray diamonds, respectively).

\section{Adsorption of IgG on NP-immobilized porous beads}

A solution of NP-immobilized porous GBs $(100 \mu \mathrm{l})$ was incubated with an aqueous solution of $\operatorname{IgG}\left(0.5 \mathrm{mg} \mathrm{ml}^{-1}, 1 \mathrm{ml}\right)$ at room temperature, and the amount of IgG remaining in the supernatant was measured using UV-Vis spectroscopy (Figure 5a). The GBs without NPs were also tested to estimate the extent of non-specific interactions of IgG with the GBs. Whereas the concentration of IgG in the supernatant decreased significantly after incubation with the NPimmobilized GBs, little difference was observed after incubation of the GBs without NPs, indicating that the IgG was captured by the NPs on the pore surface of the GBs. The amount of IgG adsorbed with $1 \mathrm{ml}$ of the GBs slurry was $\sim 3 \mathrm{mg}$.

Reversible adsorption of IgG on NP-immobilized porous beads To elute IgG that is weakly bound to the surface of NP-immobilized GBs, the GBs were washed four times with water. Then, to elute strongly bound IgG, the beads were incubated with an acidic buffer (100 mM glycine buffer, pH 2.3). Further, the GBs were regenerated with PBS and incubated with an aqueous solution of IgG. Figure $5 \mathrm{~b}$ shows the amount of IgG adsorbed and eluted by the NP-immobilized GBs. Most of the IgG adsorbed on the GBs can be eluted with an acidic buffer. The GBs can be reused at least three times. Furthermore, it was confirmed using the fluorescent measurement of the eluted solutions that bleeding of NPs was not observed at all throughout the whole reversible IgG adsorption process. These results established that NP-immobilized GBs could be used as novel affinity purification media for proteins.

\section{CONCLUSION}

In this paper, NP that bind with the $\mathrm{Fc}$ fragment of $\operatorname{IgG}$ were successfully immobilized on the pore surface of macroporous hard GB via multipoint electrostatic interactions. Scanning electron microscope established that the NPs were uniformly immobilized on the surface of the pores without blocking the macropores. $\operatorname{IgG}(3 \mathrm{mg})$, was reversibly captured by the NP-immobilized GBs through NP-IgG interactions. Macroporous hard GB with nanogel-based affinity ligands on the pore surface can be used as a novel affinity purification medium for proteins, combining an inexpensive and stable ligand and a highperformance support.

\section{ACKNOWLEDGEMENTS}

The financial support from MEXT (25107726), JSPS (23750193), Ogasawara Foundation and the Kao Foundation for Arts and Sciences is greatly appreciated.

1 Hoshino, Y., Lee, H. \& Miura, Y. Interaction between synthetic particles and biomacromolecules: fundamental study of nonspecific interaction and design of nanoparticles that recognize target molecules. Polym. J. 46, 537-545 (2014).

2 Hoshino, Y. \& Shea, K. J. The evolution of plastic antibodies. J. Mater. Chem. 21, 3517-3521 (2011)

3 Koch, S. J., Renner, C., Xie, X. \& Schrader, T. Tuning linear copolymers into protein specific hosts. Angew. Chem. Int. Ed. 45, 6352-6355 (2006).

4 Wenck, K., Koch, S., Renner, C., Sun, W. \& Schrader, T. A noncovalent switch for lysozyme. J. Am. Chem. Soc. 129, 16015-16019 (2007).

5 Arendt, M., Sun, W., Thomann, J., Xie, X. \& Schrader, T. Dendrimeric bisphosphonates for multivalent protein surface binding. Chem. Asia J. 1, 544-554 (2006).

6 Dernedde, J., Rausch, A., Weinhart, M., Enders, S., Tauber, R., Licha, K., Schirner, M., Zügel, U., von Bonin, A. \& Haag, R. Dendritic polyglycerol sulfates as multivalent inhibitors of inflammation. Proc. Natl Acad. Sci. USA 107, 19679-19684 (2010).

7 Weinhart, M., Groger, D., Enders, S., Riese, S. B., Dernedde, J., Kainthan, R. K. Brooks, D. E. \& Haag, R. The role of dimension in multivalent binding events: structure-activity relationship of dendritic polyglycerol sulfate binding to L-selectin in correlation with size and surface charge density. Macromol. Biosci. 11 1088-1098 (2011)

8 Weinhart, M., Groger, D., Enders, S., Dernedde, J. \& Haag, R. Synthesis of dendritic polyglycerol anions and their efficiency toward L-selectin inhibition. Biomacromolecules 12, 2502-2511 (2011).

9 Cabaleiro-Lago, C., Quinlan-Pluck, F., Lynch, I., Lindman, S., Minogue, A. M. Thulin, E., Walsh, D. M., Dawson, K. A. \& Linse, S. Inhibition of amyloid $\beta$ protein fibrillation by polymeric nanoparticles. J. Am. Chem. Soc. 130, 15437-15443 (2008).

10 Hoshino, Y., Urakami, T., Kodama, T., Koide, H., Oku, N., Okahata, Y. \& Shea, K. J. Design of synthetic polymer nanoparticles that capture and neutralize a toxic peptide. Small 5, 1562-1568 (2009).

11 Yoshimatsu, K., Yamazaki, T., Hoshino, Y., Rose, P. E., Epstein, L. F., Miranda, L. P., Tagari, P., Beierle, J. M., Yonamine, Y. \& Shea, K. J. Epitope discovery for a synthetic polymer nanoparticle: a new strategy for developing a peptide tag. J. Am. Chem. Soc. 136, 1194-1197 (2014).

12 Yonamine, Y, Hoshino, Y. \& Shea, K. J. An ELISA-mimic screen for synthetic polymer nanoparticles with high affinity to target proteins. Biomacromolecules 13 2952-2957 (2012).

13 Yoshimatsu, K., Lesel, B. K., Yonamine, Y., Beierle, J. M., Hoshino, Y. \& Shea, K. J. Temperature-responsive "catch and release" of proteins by using multifunctional polymer-based nanoparticles. Angew. Chem. Int. Ed. 51, 2405-2408 (2012).

14 Hoshino, Y., Nakamoto, M. \& Miura, Y. Control of protein-binding kinetics on synthetic polymer nanoparticles by tuning flexibility and inducing conformation changes of polymer chains. J. Am. Chem. Soc. 134, 15209-15212 (2012).

15 Nakamoto, M., Hoshino, Y. \& Miura, Y. Effect of physical properties of nanogel particles on the kinetic constants of multipoint protein recognition process. Biomacromolecules 15, 541-547 (2014). 
16 Lee, S.-H., Hoshino, Y., Randall, A., Zeng, Z., Baldi, P., Doong, R. \& Shea, K. J. Engineered synthetic polymer nanoparticles as IgG affinity ligands. J. Am. Chem. Soc. 134, 15765-15772 (2012).

17 Weisman, A., Chen, Y. A., Hoshino, Y. \& Shea, K. J. Engineering nanoparticle antitoxins utilizing aromatic interactions. Biomacromolecules 15, 3290-3295 (2014).

18 Yonamine, Y., Yoshimatsu, K., Lee, S.-H., Hoshino, Y., Okahata, Y. \& Shea, K. J. Polymer nanoparticle-protein interface. Evaluation of the contribution of positively charged functional groups to protein affinity. ACS Appl. Mater. Interfaces 5, 374-379 (2013)

19 Hoshino, Y., Koide, H., Furuya, K., Haberaecker, W. W. III, Lee, S.-H., Kodama, T., Kanazawa, H., Oku, N. \& Shea, K. J. The rational design of a synthetic polymer nanoparticle that neutralizes a toxic peptide in vivo. Proc. Natl Acad. Sci. USA 109, 33-38 (2012)

20 Hoshino, Y., Kodama, T., Okahata, Y. \& Shea, K. J. Peptide imprinted polymer nanoparticles: a plastic antibod. J. Am. Chem. Soc. 130, 15242-15243 (2008).

21 Hoshino, Y., Ohashi, R. C. \& Miura, Y. Rational design of synthetic nanoparticles with a large reversible shift of acid dissociation constants: proton imprinting in stimuli responsive nanogel particles. Adv. Mater. 26, 3718-3723 (2014).

22 Hoshino, Y., Haberaecker, W. W. III, Kodama, T., Zeng., Z., Okahata, Y. \& Shea, K. J. Affinity purification of multi functional polymer nanoparticles. J. Am. Chem. Soc. 132, 13648-13650 (2010).

23 Seto, H., Ogata, Y., Murakami, T., Hoshino, Y. \& Miura, Y. Selective protein separation using siliceous materials with a trimethoxysilane-containing glycopolymer. ACS Appl. Mater. Interfaces 4, 411-417 (2012).

24 Seto, H., Takara, M., Yamashita, C., Murakami, T., Hasegawa, T., Hoshino, Y. \& Miura, Y. Surface modification of siliceous materials using maleimidation and various functional polymers synthesized by reversible addition-fragmentation chain transfer polymerization. ACS Appl. Mater. Interfaces 4, 5125-5133 (2012).

25 Ogata, Y., Seto, H., Murakami, T., Hoshino, Y. \& Miura, Y. Affinity separation of lectins using porous membranes immobilized with glycopolymer brushes containing mannose or N-acetyl-D-glucosamine. Membranes 3, 169-181 (2013).

26 Hober, S., Nord, K. \& Linhult, M. Protein A chromatography for antibody purification. J. Chromatogr. B 848, 40-47 (2007).
27 Katoh, S., Imada, M., Takda, N., Katsuda, T., Miyahara, H., Inoue, M. \& Nakamura, S. Optimization of silica-based media for antibody purification by protein A affinity chromatography. J. Chromatogr. A 1161, 36-40 (2007).

28 Perez-Almodovar, E. X. \& Carta, G. IgG adsorption on a new protein A adsorbent based on macroporous hydrophilic polymers. I. Adsorption equilibrium and kinetics. J. Chromatogr. A 1216, 8339-8347 (2009).

29 Kelly, B. Very large scale monoclonal antibody purification: the case for conventional unit operations. Biotechnol. Prog. 23, 995-1008 (2007).

30 Kusano, H., Miyata, E., Takayanagi, H., Itagaki, T. High Performance Liquid Chromatography in Biotechnology (ed. Hancock W. S.) Ch. 5, 91-116 (John Wiley \& Sons: Hoboken, NJ, USA 1990).

31 Takayanagi, H., Ito, T., Kubo, Y. \& Kusano, H. Sepabeads FP series: New packing materials for industrial-scale separation of biopolymers. Chromatographia 25, 647-651 (1988)

32 Tokunaga, K. \& Tsuhara, R. Bunrizai. Patent JP 2012/018135 A (2012)

33 Serpe, M. J., Jones, C. D. \& Lyon, L. A. Layer-by-layer deposition of thermoresponsive microgel thin films. Langmuir 19, 8759-8764 (2003).

34 Nolan, C. M., Serpe, M. J. \& Lyon, L. A. Thermally modulated insulin release from microgel thin films. Biomacromolecules 5, 1940-1946 (2004).

35 Serpe, M. J., Yarmey, K. A., Nolan, C. M. \& Lyon, L. A. Doxorubicin uptake and release from microgel thin films. Biomacromolecules 6, 408-413 (2005).

This work is licensed under a Creative Commons Attribution-NonCommercial-NoDerivs 3.0 Unported License. The images or other third party material in this article are included in the article's Creative Commons license, unless indicated otherwise in the credit line; if the material is not included under the Creative Commons license, users will need to obtain permission from the license holder to reproduce the material. To view a copy of this license, visit http://creativecommons.org/licenses/by-nc-nd/3.0/ 